Gem Testing

By B. W. Anderson. Sixth edition, revised and reset. Pp. 324. (London: Heywood and Co., Ltd., 1958.) 42s. net.

A CENTURY ago the identification of gemstones was the speciality of experts in the trade who, by long experience and from lore handed on from masters to apprentices, had learned to judge their gemstones by sight and touch with little beyond a lens and perhaps a file to help them. The use of simple scientific methods for determining density and the optical characters of gemstones as a means of identification had long been advocated by a few enthusiasts but not generally adopted. It was not until the appearance on the market of synthetic rubies, sapphires and spinels that the scientific methods began to gain more general acceptance. New methods had to be devised to distinguish natural from synthetic stones and, later, to distinguish cultured pearls from natural ones. The London Chamber of Commerce set up a laboratory for testing diamonds, pearls and precious stones, the Gemmological Association of Great Britain was founded, and lecture courses on gemmological subjects wore commenced. The author of this book is the head of the laboratory and for many years he has taught and examined for the Association. His book is the best on this subject, and in the sixth edition there is much that is new.

The author is a strong advocate of the use of a direct-vision spectrometer for identification of gemstones by their absorption spectra, and the chapter on this part of the subject has been largely re-arranged and illustrated.

A neat method of comparing the refractive indices of a number of gemstones is described. It depends on observing, or photographing, the shadows the stones throw when immersed in a liquid with refractive index near their own while illuminated from above. The use of a contact photograph and ultra-violet light can be made to show at a glance the difference betweeen natural and synthetic rubies, the latter being definitely more transparent to ultraviolet light. More use is being made of the study of inclusions in gemstones, a branch of the subject extensively studied by Dr. E. Gübelin of Berne. Many of his photomicrographs of inclusions are used in this book.

These are only a few of the tests the author describes.

W. Campbell Smith

Behavior and Psychological Man

Essays in Motivation and Learning. By Prof, Edward Chace Tolman. Pp. xiv +269. (Berkeley and Los Angeles: University of California Press; London : Cambridge University Press, 1958.) 1.95 dollars ; 17s. $6 d$.

HIS volume is a reprint of Tolman's "Collected

Papers in Psychology" first published in 1951 and it includes a warm and appreciative foreword by his colleagues at the University of California. The papers have been chosen to indicate the successive stages in the development of Tolman's theoretical system.

Prof. Tolman's contributions to psychological theory and experiment are equally outstanding. This will be granted without necessarily sharing his views. $\mathrm{He}$ is the exponent of 'molar' behaviourism, in contrast to the 'molecular' behaviourism of the school of Clark Hull at Yale; and he has gone further than any other behaviourist in trying to embrace within his system essential features of Gestalt, psychoanalytic, and hormic theory in terms of operationally defined variables.

The considerable achievements of Prof. Tolman mark a characteristic phase in the development of psychology. His experimental work, however, must be disentangled from its theoretical framework. The latter rests on a positivistic philosophy the validity of which is not self-evident. Indeed, it would seem that the behaviouristic positivism pursued by Prof. Tolman in the interests of scientific rigour has, in fact, been detrimental to the psychological 'all-inclusiveness' to which his system aspires. JoHN CoHEN

\section{The Excitable Cortex in Conscious Man}

By Dr. Wilder Penfield. (The Sherrington Lectures, 5.) Pp. ix + 43. (Liverpool : Liverpool University Press, 1958.) 10s. 6d. net.

7 HIS book presents a summarized version of the data which the author has accumulated from the responses to electrical stimulation of the cerebral cortex during operations on the human brain. It also elaborates the author's hypothesis of a 'centrencephalic system' within the brain, concerned with higher integrative processes. The sensations which patients describe when the visual, auditory or somatic sensory area of the cortex is stimulated, are discussed, together with the movements elicited by stimulation of the motor cortex. The effects of stimulation of the temporal lobe, particularly psychic responses, are dealt with in more detail and in relation to temporal lobe epilepsy. The author points out that the clinician must contribute to science "as best he can from very different material and as chance presents it". Certainly he appear's to have made good use of the material available to him in his long experience as a neurosurgeon.

While the book contains little that is not available in the other writings of this author, it presents this material in a very acceptable form, well illustrated, and with clinical examples. It should be easily understood by those with little knowledge of neurology and to the student it provides a useful introduction to this field of research.

P. B. BradLEy

\section{Information Service in Libraries}

By D. J. Foskett. (Crosby Lockwood's New Librarianship Series.) Pp. vii +142. (London: Crosby, Lockwood and Son, Ltd., 1958.) 13s. 6d. net.

TN this little volume Mr. D. J. Foskett presents a concise but thoroughly competent survey of the development of information service in libraries and the various aspects of that work to-day, as well as the qualifications demanded of those who carry such responsibilities. To anyone contemplating such a career he offers much sound advice, while to those already occupying posts as information officers or as librarians he indicates problems where further thought and much closer co-operation are needed. Mr. Foskett does not hesitate to express his own opinions or preferences ; but his point of view is always reasonably argued and it is incidentally rather than by direct attack that he shows how trivial is the attempt to draw a division to-day between the librarian and the information officer or between the handling of scientific and technical literature or any other form of literature. The bibliographies appended to his several chapters are adequate and balanced, and this book should both provoke useful debate and help the beginner to master his profession. R. BRIGHTMAN 